Gorges, C.; Öztürk, K.; Liebich, R.

\title{
Customer loads of two-wheeled vehicles
}

Journal article | Accepted manuscript (Postprint)

This version is available at https://doi.org/10.14279/depositonce-8143

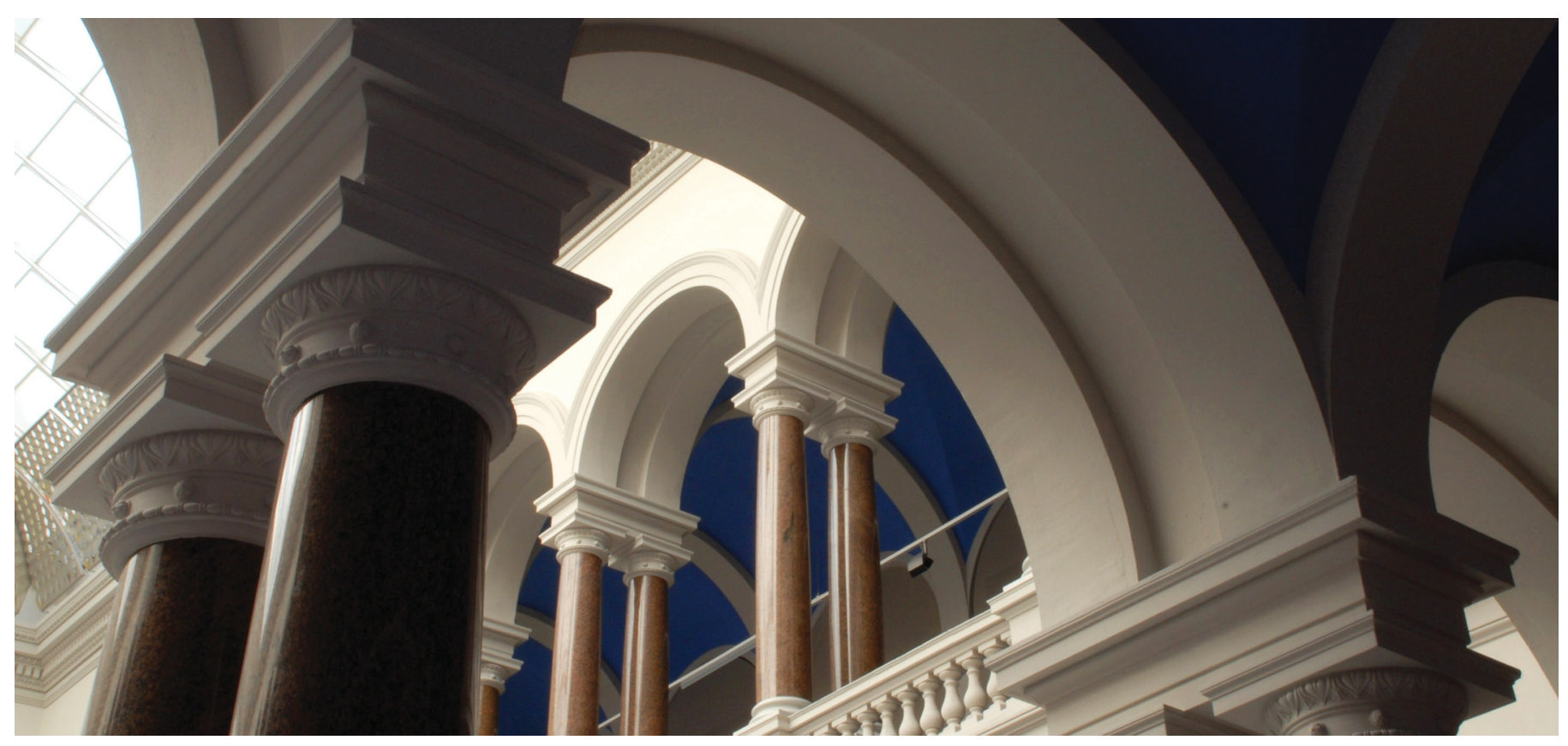

Gorges, C., Öztürk, K., \& Liebich, R. (2017). Customer loads of two-wheeled vehicles. Vehicle System Dynamics, 55(12), 1842-1864.

https://doi.org/10.1080/00423114.2017.1335874

This is an Accepted Manuscript of an article published by Taylor \& Francis in Vehicle System Dynamics on 13 June 2017, available online:

http://www.tandfonline.com/10.1080/00423114.2017.1335874.

\section{Terms of Use}

Copyright applies. A non-exclusive, non-transferable and limited right to use is granted. This document is intended solely for 


\title{
Customer loads of two-wheeled vehicles
}

\author{
Christian Gorges ${ }^{\mathrm{a}}$, Kemal ÖZtürk ${ }^{\mathrm{a}}$, Robert Liebich ${ }^{\mathrm{b}}$ \\ ${ }^{\mathrm{a}} B M W$ AG, Munich, Germany: ${ }^{\mathrm{b}}$ Chair of Engineering Design and Product Reliability, \\ Berlin Institute of Technology, Berlin, Germany
}
(This is an Accepted Manuscript of an article published by Taylor 8 Francis in Vehicle System Dynamics on 13/06/2017, available online: http://www. tandfonline. com/10.1080/00423114. 2017. 1335874.)

Customer usage profiles are the most unknown influences in vehicle design targets and they play an important role in durability analysis. This publication presents a customer load acquisition system for two-wheeled vehicles that utilises the vehicle's onboard signals. A road slope estimator was developed to reveal the unknown slope resistance force with the help of a linear Kalman filter. Furthermore, an automated mass estimator was developed to consider the correct vehicle loading. The mass estimation is performed by an extended Kalman filter. Finally, a model-based wheel force calculation was derived, which is based on the superposition of forces calculated from measured onboard signals. The calculated wheel forces were validated by measurements with wheel-load transducers through the comparison of rainflow matrices. The calculated wheel forces correspond with the measured wheel forces in terms of both quality and quantity. The proposed methods can be used to gather field data for improved vehicle design loads.

Keywords: Customer loads, motorcycle dynamics, road slope estimation, mass estimation, load acquisition, Kalman filter

\section{Introduction}

Two-wheeled vehicles are characterised by diverse application possibilities, given that motorcycles have changed from means of transportation to general purpose vehicles, at least in the modern world. Scooters and small-sized motorcycles remain the first choice for personal mobility in urban traffic, whereas more specific vehicle segments such as Enduro, Sport, Cross, Tour, Roadster and Cruiser exist for individual purposes. Since mass reduction and lightweight design play an important role in vehicle engineering, the components are optimised to their individual design targets. Consequently, every product segment needs its own requirements regarding durability and operating strength. Furthermore, different markets with varying regional demands influence product design [1]. The most unknown influences to determine vehicle design targets are customer usage profiles. Detailed knowledge of customer usage profiles improves design loads and ultimately the vehicle development process. Customer usage profiles describe the unknown distribution comprising wheel forces, vehicle loading, road profile characteristics, engine loads, brake events, and special events. In this paper, customer loads are defined as wheel forces and vehicle loading. Knowledge about the vehicle loading is particularly 


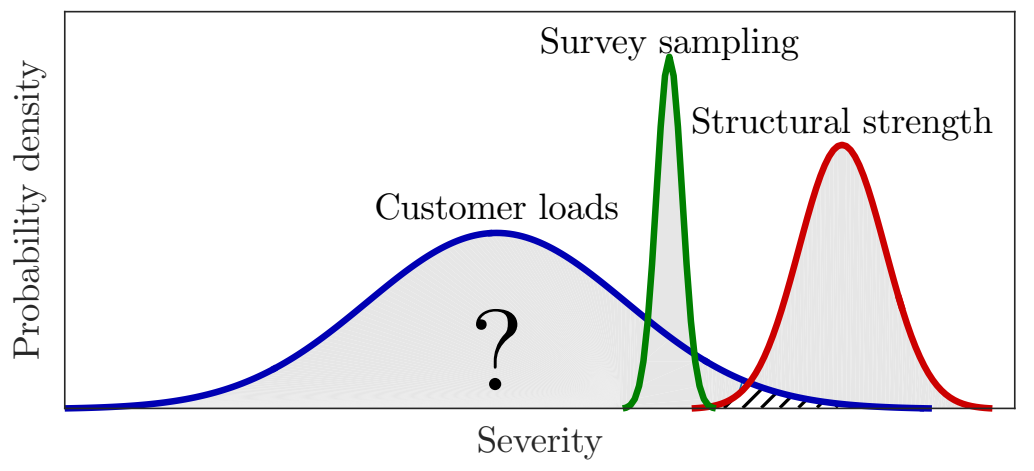

Figure 1 - Distribution of customer loads, survey sampling, and structural strength.

important for two-wheeled vehicles and has a strong impact on the customer loads, given that the vehicle's empty weight is low in comparison to the additional loading comprising the driver, passenger, and luggage weight.

At present, a common method to obtain field data is survey sampling, where a certain number of test vehicles are equipped with additional measurement devices to perform a measurement campaign with selected or randomly chosen customers. However, survey sampling cannot reveal the complete probability distribution of customer loads. Moreover, it is expensive due to the additional equipment costs. Figure 1 illustrates the broad probability density function of customer loads in comparison to the structural strength of the components and the narrow distribution of survey samplings. To reveal the entire distribution of customer loads, every customer would have to be evaluated. Johannesson and Speckert [1] highlight that there are two scales when discussing customer loads: on the small scale the profile of a specific customer needs to be evaluated; while on the large scale, the problem is to identify the severity of a population of customers. The final vehicle design loads involve combining survey sampling, measurements on test tracks, and experience from previous product designs.

The number of onboard sensors rises due to the increased functions of motorcycles, such as an anti-lock braking system (ABS), dynamic traction control (DTC), or curve assistant. Hence, the main approach of this study is to gather information from every customer with the help of these onboard signals. Onboard signals are defined as signals that can be accessed by the vehicle's Controller Area Network (CAN) bus and are part of every production vehicle. This type of field data collection can be classified as a modelbased online monitoring system with integrated counting of durability-related values. Online implies that the customer loads are estimated while the vehicle is in use, meaning that there is no long-term logging of the signals. Several of these systems have already 


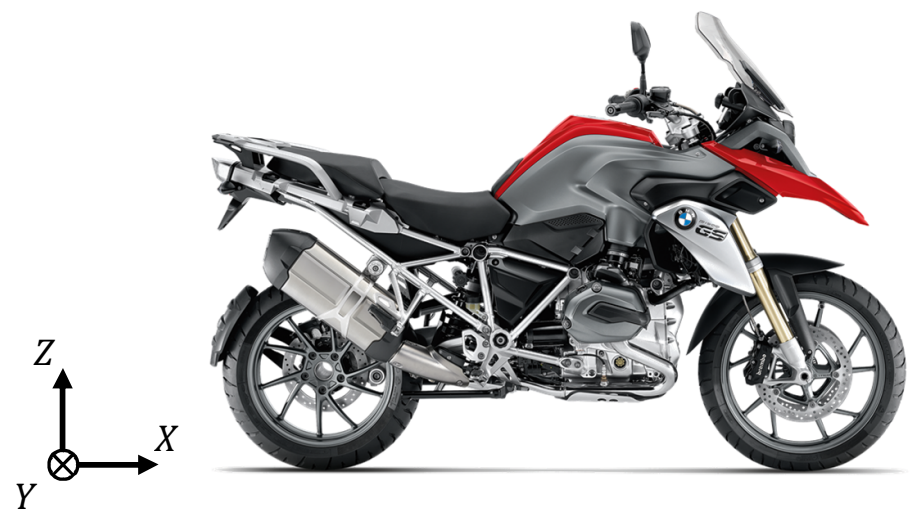

Figure 2 - Test motorcycle with the global reference coordinate system (c)BMW AG.

been published in vehicle engineering. Müller [2] simulated operative stresses on critical parts of commercial vehicles within a multi-body system model in real time. She has used measured acceleration data as input for the simulation and counted the resultant stresses online with the help of the rainflow counting method. In contrast to Müller, Matz [3] directly calculated the wheel forces of passenger cars and then translated these forces acting on components with kinematic transfer functions. His approach also has used onboard signals as inputs. Karlsson [4] has presented different methods to model loads for customer usage profiles with the help of road classification.

In contrast to specific application-driven publications, the main contribution of this study is to develop a holistic approach to collect customer loads with onboard signals of two-wheeled vehicles. There is neither the ambition to realise a real-time control system nor to intervene vehicle dynamics. Therefore, no specific hardware requirements will be discussed. This paper is organised as follows. Section 2 describes the reference motorcycle with measurement equipment and analyses previously measured wheel forces which serve as reference values. Section 3 derives the algorithms for road slope estimation, mass estimation, and the calculation of wheel forces. Section 4 discusses and compares the results from simulation to their reference measurements to validate the method. Finally, Section 5 provides a summary and conclusion about the developed methods.

\section{Experimental set-up and data analysis}

A motorcycle with data-logging devices was prepared for experimental tests and validation of the algorithms. Onboard signals were logged during pre-defined tracks for offline simulation of vehicle dynamics. Figure 2 shows the test and reference motorcycle (BMW 
R1200GS) together with the global reference coordinate system. The reference frame will not rotate around the roll axes during banking of the motorcycle, which means that it is aligned with the road plane. When the motorcycle is upright, it coincides with the vehicle's coordinate system. The test motorcycle has the following onboard signals available, which are required for the developed algorithms:

- 5 DOF Inertial Measurement Unit (IMU) to measure

- Acceleration in $X, Y$, and $Z$ in the vehicle coordinate system.

- Angular velocity around $X$ (roll) and $Z$ (yaw) in the vehicle coordinate system.

- wheel velocities,

- brake pressures,

- spring deflections,

- model-based signals (e.g. engine torque and roll angle).

These signals were logged through the CAN bus. Additionally, the vehicle was equipped with a Global Positioning System (GPS) logging device, which provides information about the position and the altitude for later validation.

Wheel forces were measured with wheel-load transducers [5] during previous measurement campaigns. These forces were used for data analysis and validation of the wheel force calculation. Figure 3 shows a generic amplitude spectrum of vertical wheel forces. The amplitude spectrum can be divided into two domains: the first domain contains driver-induced forces and low-frequency path excitation from road undulations; and the second domain contains track-induced forces from stochastic road excitation. These two domains are separated by the crossover frequency $f_{\mathrm{c}}$. It is well known that these two domains belong to the different modes of the motorcycle [6]. The first domain contains bounce and pitch mode of the sprung mass, while the second domain contains wheel hop modes of unsprung masses. Driver-induced forces are defined as forces directly dedicated to driver manoeuvres, such as accelerating, braking, and cornering. The main aspect of this analysis is to highlight the crossover frequency $f_{\mathrm{c}}$, which is used to set up the filter frequency for the wheel force calculation, see Section 3.4.

The logged signals from the previous measurement campaigns were used in a Simulink ${ }^{\circledR}$ model to simulate vehicle dynamics and validate the developed algorithms. The discrete model uses the same time step size as the vehicle's onboard time step size. This in principle enables an online application of the developed algorithms. It is not part of the present study to evaluate specific hardware requirements for implementation of the methods into existing or new production vehicles. 


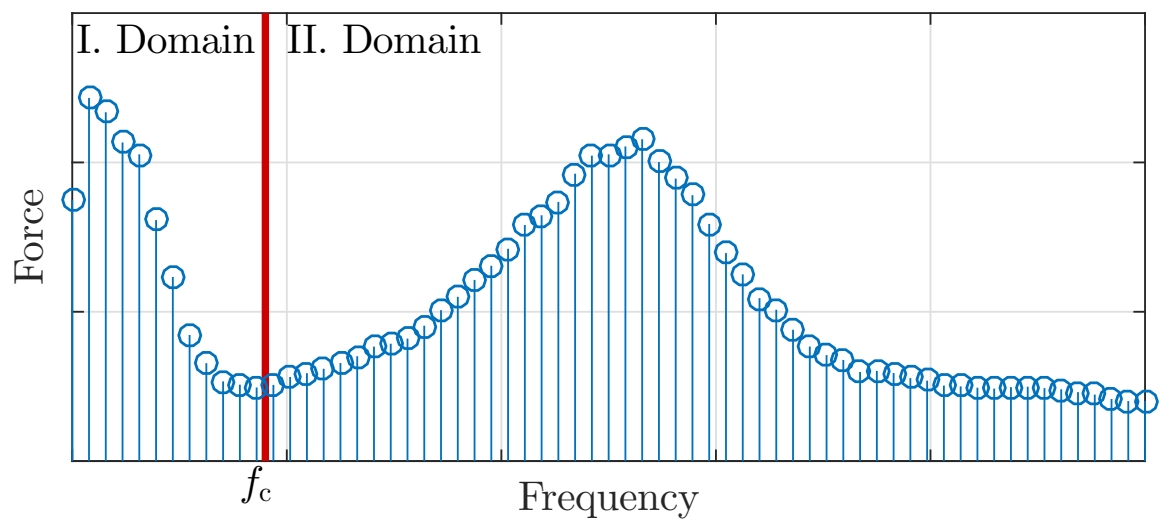

Figure 3 - Amplitude spectrum of vertical wheel forces.

\section{Methods}

The wheel force calculation requires all resistance forces that act on the motorcycle. Therefore, two unknown resistance forces had to be determined first: the slope resistance force and the inertial force. A road slope estimator based on a linear Kalman filter (KF) was developed, which estimates the current road slope angle. The total vehicle mass comprises the motorcycle and the loading, including the driver, passenger, and luggage weight. The estimation of the total vehicle mass was developed with the help of an extended Kalman filter. The mass estimator requires the road slope angle and the traction force as input signals. A stiff driveline model was used to calculate the traction force from the internal engine torque. Once the vehicle mass and the road slope had been determined, the wheel force calculation was feasible. The wheel forces were calculated by a superposition of forces calculated from measured motions. Subsequently, the wheel forces were counted with the rainflow method, which reduces the memory requirements and enables a classification of the customer loads.

\subsection{Road slope estimator}

Estimation of the road slope is essential for the wheel force calculation, since road slope can cause a major driving resistance force. Different methods for the estimation of road slope have already been published. Boniolo et al. [7] utilised a 6-DOF IMU to describe the state of the motorcycle with Euler angles. Moreover, they used an extended KF to estimate the vehicle states. Since a 6-DOF IMU is not yet part of the onboard signals, this method will not be adopted for the present work. Vahidi et al. [8] estimated the road slope together with the mass of a heavy-duty vehicle using a recursive least-square estim- 


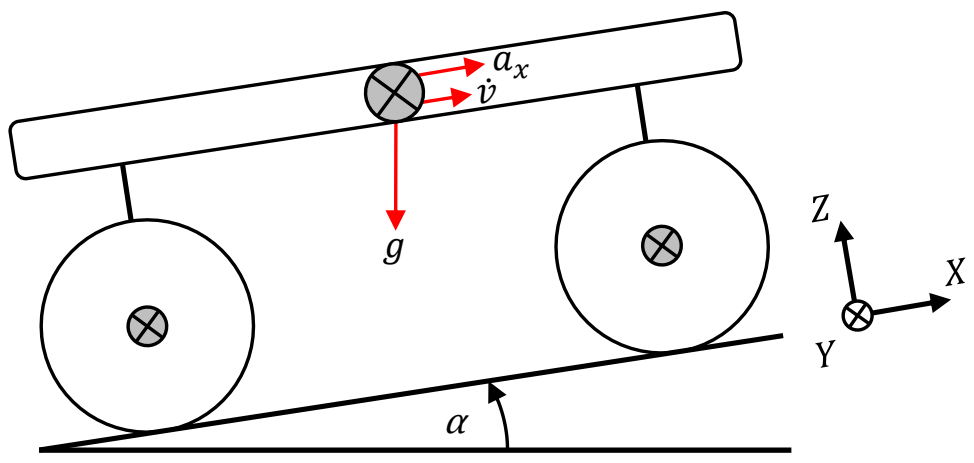

Figure 4 - Road slope estimation physics.

ation with forgetting factor. Lingman and Schmidtbauer [9] reported another example for this type of slope estimation, while they used an extended KF. The aforementioned methods use driving resistance forces and longitudinal dynamics for the estimation problem. This paper uses a similar approach described by Corno et al. [10], because it is more suitable for the application to motorcycles. The idea is that the gravitational acceleration is measured by the IMU in longitudinal direction while riding up- or downhill, see Figure 4. Assuming a rigid motorcycle, the estimated pitch angle is the road slope angle $\alpha$. In contrast to the other methods, this approach makes the estimation of the road slope independent from the mass estimation. The road slope angle can be calculated directly with the help of the inertial acceleration $a_{x}$ and the vehicle acceleration $\dot{v}$, which is derived from the wheel velocities. Hence, the road slope angle $\alpha$ is given by

$$
\alpha=\arcsin \frac{a_{x}-\dot{v}}{g} .
$$

Since the input signals are affected by noise from both measurement and differentiation, a linear KF [11] was implemented to estimate the road slope. Many applications have been realised with Kalman filtering, particularly in navigation problems, as well as vehicle dynamics. Maybeck [12] describes the KF as a recursive data-processing algorithm that minimises the error statistically [13]. To estimate the road slope with the linear KF, the discrete linear difference equation needs to be derived. Therefore, the problem was formulated in state-space representation. The state vector $\boldsymbol{x}_{\mathrm{s}} \in \operatorname{Re}^{n}$ comprises the velocity $v$ and $\Phi$, as shown in Equation (2).

$$
\boldsymbol{x}_{\mathrm{s}}=\left(\begin{array}{c}
v \\
\Phi
\end{array}\right), \quad \Phi=\sin \alpha
$$


The subscript 's' indicates that the state vector is formulated to estimate the slope. The substitution of $\Phi=\sin \alpha$ leads to a linear formulation of the system, which is essential to apply the linear KF. The measurement vector $\boldsymbol{z}_{\mathrm{s}} \in \operatorname{Re}^{m}$ is defined by the measured velocity $v$, which can be derived from the rotational speed of the wheels and is part of the onboard signals. Transformation of Equation (1) yields the state-space representation of the problem, see Equation (3).

$$
\dot{\boldsymbol{x}}_{\mathrm{s}}=\left(\begin{array}{c}
a_{x}-g \Phi \\
0
\end{array}\right), \quad \boldsymbol{z}_{\mathrm{s}}=v .
$$

To apply the linear KF, the explicit discrete time-invariant formulation of the problem must be derived. This is achieved by using the explicit Euler forward integration, whereby $s$ is the time step size:

$$
\boldsymbol{x}_{\mathrm{s} \mid k}=\left(\begin{array}{c}
v_{k} \\
\Phi_{k}
\end{array}\right)=\left(\begin{array}{c}
v_{k-1}+s\left[a_{x \mid k-1}-g \Phi_{k-1}\right]+q_{\mathrm{s}_{1} \mid k-1} \\
\Phi_{k-1}+q_{\mathrm{s}_{2} \mid k-1}
\end{array}\right) .
$$

Process and measurement noise is represented by $\boldsymbol{q}_{\mathrm{s}}$ and $\boldsymbol{r}_{\mathrm{s}}$, respectively. They are assumed to be independent and uncorrelated with a normal white noise probability distribution [13]:

$$
\begin{aligned}
& p\left(\boldsymbol{q}_{\mathrm{s}}\right) \sim N\left(0, \mathbf{Q}_{\mathrm{S}}\right), \\
& p\left(\boldsymbol{r}_{\mathrm{s}}\right) \sim N\left(0, \mathbf{R}_{\mathrm{S}}\right) .
\end{aligned}
$$

$\mathbf{Q}_{\mathrm{S}}$ is the process noise covariance matrix and $\mathbf{R}_{\mathrm{S}}$ is the measurement noise covariance matrix. Equation (4) is reformulated into the linear stochastic difference Equation (7) with measurement Equation (8).

$$
\begin{aligned}
& \boldsymbol{x}_{\mathrm{s} \mid k}=\underbrace{\left[\begin{array}{cc}
1 & -s g \\
0 & 1
\end{array}\right]}_{\mathbf{A}_{\mathrm{s}}} \underbrace{\left(\begin{array}{c}
v_{k-1} \\
\Phi_{k-1}
\end{array}\right)}_{\boldsymbol{x}_{\mathrm{s} \mid k-1}}+\underbrace{\left[\begin{array}{c}
s \\
0
\end{array}\right]}_{\mathbf{B}_{\mathrm{s}}} \underbrace{a_{x \mid k-1}}_{\boldsymbol{u}_{\mathrm{s} \mid k-1}}+\underbrace{\left[\begin{array}{cc}
1 & 0 \\
0 & 1
\end{array}\right]\left(\begin{array}{c}
q_{\mathrm{s}_{1} \mid k-1} \\
q_{\mathrm{s} 2} \mid k-1
\end{array}\right)}_{\boldsymbol{q}_{\mathrm{s} \mid k-1}}, \\
& \boldsymbol{z}_{\mathrm{s} \mid k}=\underbrace{\left[\begin{array}{cc}
1 & 0
\end{array}\right]}_{\mathbf{H}_{\mathrm{s}}} \underbrace{\left(\begin{array}{c}
v_{k} \\
\Phi_{k}
\end{array}\right)+r_{\mathrm{s} \mid k} .}_{\boldsymbol{x}_{\mathrm{s} \mid k}}
\end{aligned}
$$


The $n \times n$ linear system matrix $\mathbf{A}_{\mathrm{s}}$ relates the state $\boldsymbol{x}_{\mathrm{s}}$ at the previous time step $k-1$ to the state at the current time step $k$. The linear $n \times l$ input matrix $\mathbf{B}_{\mathrm{s}}$ relates the control input vector $\boldsymbol{u}_{\mathrm{s}} \in \operatorname{Re}^{l}$ to the state $\boldsymbol{x}_{\mathrm{s}}$, while the inertial acceleration $a_{x}$ is defined as the control input. The linear $m \times n$ measurement matrix $\mathbf{H}_{\mathrm{s}}$ relates the state $\boldsymbol{x}_{\mathrm{s}}$ to the measurement $\boldsymbol{z}_{\mathrm{s}}$.

In comparison to the direct computation, see Equation (1), this formulation does not require a differentiation of the velocity $v$ to obtain the road slope. The measurement noise covariance matrix was estimated from previous measurements of the velocity $v$ and was thus set to $\mathbf{R}_{\mathrm{s}}=0.01$. The system covariance matrix $\mathbf{Q}_{\mathrm{s}}$ was tuned empirically, which is a standard practice in KF application. In contrast to the rigid motorcycle model, a real motorcycle has a degree of freedom around the $Y$-axis (pitch). Therefore, an on/off logic was implemented to restrict the pitch influence on the road slope estimation. Since the test motorcycle has no pitch signal available, the longitudinal acceleration was utilised to detect acceleration and brake events. Thus, the road slope estimation pauses when a certain value of longitudinal acceleration is exceeded. Furthermore, the model assumptions are only valid for motorcycles without steering action. The algorithm thus also pauses when the measured angular yaw rate exceeds a certain value. To sum up, the following restrictions were formulated for the road slope estimator:

- Absolute value of the angular yaw rate is lower than a given threshold.

- Absolute value of the longitudinal acceleration is lower than a given threshold.

When at least one condition is violated, the algorithm holds the road slope estimation until the conditions are true again. In the meantime, the last valid value of the road slope is delivered for the mass estimator and the wheel force calculation. Please note that these limitations are only valid for the road slope estimator. They are independent of the mass estimator and the wheel force calculation.

\subsection{Driveline model}

The mass estimation and the wheel force calculation require the traction force $F_{\mathrm{T}}$. Thus, the traction force was derived from the rotational equations of motion from both the driveline and the rear-wheel dynamics, as illustrated in Figure 5 . The engine torque $T_{\mathrm{e}}$ is provided by the engine electronic control unit (ECU). It is calculated by the engine speed and the throttle position. The engine torque already considers the necessary amount of slip to accelerate the vehicle, because the engine torque is adapted to the current road conditions due to the DTC. The driveline is assumed to be stiff, whereby driveline oscillation and torsional effects are neglected. The transmission torque $T_{\mathrm{t}}$ can be calculated 


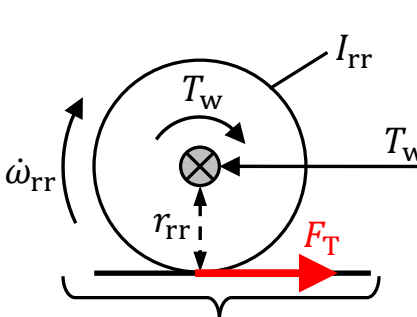

Rear wheel

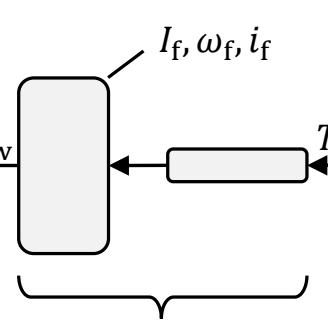

Cardan drive \& Differential

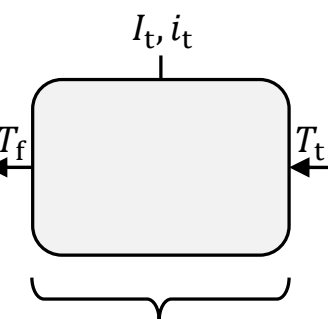

Transmission

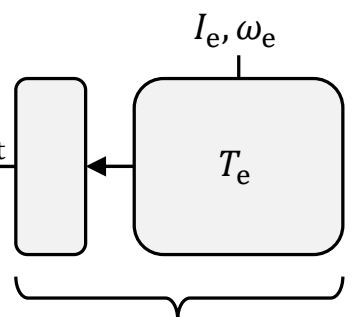

Engine \& Clutch

Figure 5 - Model of the driveline dynamics.

by subtracting the rotational inertia of the engine components $I_{\mathrm{e}}$ from the engine torque $T_{\mathrm{e}}$, as shown in Equation (9).

$$
\begin{aligned}
T_{\mathrm{t}} & =T_{\mathrm{e}}-I_{\mathrm{e}} \dot{\omega}_{\mathrm{e}}, \\
T_{\mathrm{f}} & =\left(T_{\mathrm{t}}-I_{\mathrm{t}} \dot{\omega}_{\mathrm{e}}\right) i_{\mathrm{t}}, \\
T_{\mathrm{w}} & =\left(T_{\mathrm{f}}-I_{\mathrm{f}} \dot{\omega}_{\mathrm{f}}\right) i_{\mathrm{f}} .
\end{aligned}
$$

The final drive torque $T_{\mathrm{f}}$ can be calculated by subtracting the inertial losses of the transmission parts $I_{\mathrm{t}}$ from the transmission torque $T_{\mathrm{t}}$. Furthermore, it is amplified by the gear ratio $i_{\mathrm{t}}$, see Equation (10). The wheel torque $T_{\mathrm{w}}$ is derived from the final drive torque $T_{\mathrm{f}}$ reduced by the inertial losses of the cardan drive and the differential $I_{\mathrm{f}}$. Furthermore, it is amplified by the fixed final drive ratio $i_{\mathrm{f}}$, see Equation (11). The traction force $F_{\mathrm{T}}$ can be derived from the rotational equation of motion of the rear wheel, see Equation (12), where $r_{\mathrm{rr}}$ is the dynamic rolling radius of the rear wheel.

$$
\begin{gathered}
I_{\mathrm{rr}} \dot{\omega}_{\mathrm{rr}}=T_{\mathrm{w}}-F_{\mathrm{T}} r_{\mathrm{rr}} \\
\dot{\omega}_{\mathrm{rr}}=\frac{\dot{v}}{r_{\mathrm{rr}}}, \quad u=\frac{i_{\mathrm{tf}}}{r_{\mathrm{rr}}}, \quad i_{\mathrm{tf}}=i_{\mathrm{t}} i_{\mathrm{f}}, \quad \mu_{\mathrm{eff}}=\text { efficiency parameter. }
\end{gathered}
$$

Moreover, it is assumed that the rolling condition is valid. The gear ratio $i_{\mathrm{t}}$, the final drive ratio $i_{\mathrm{f}}$, and the dynamic rear-wheel radius $r_{\text {rr }}$ are condensed into the coefficient $u$. The rotational acceleration of the rear wheel $\dot{\omega}_{\text {rr }}$ can be derived from the rear-wheel velocity $v$. Mechanical losses of the driveline are reduced to the efficiency parameter $\mu_{\mathrm{eff}}$, see Equation (13). Finally, the traction force $F_{\mathrm{T}}$ can be partitioned into two parts: the 
steady-state traction force and the losses of the traction force due to the driveline inertia, as shown in Equation (14).

$$
F_{\mathrm{T}}=\frac{T_{\mathrm{w}}-I_{\mathrm{rr}} \dot{\omega}_{\mathrm{rr}}}{r_{\mathrm{rr}}}=\underbrace{T_{\mathrm{e}} u \mu_{\mathrm{eff}}}_{\text {Steady-state }}-\underbrace{\left(I_{\mathrm{e}}+I_{\mathrm{t}}+\frac{I_{\mathrm{f}}}{i_{\mathrm{t}}^{2}}+\frac{I_{\mathrm{rr}}}{i_{\mathrm{tf}}^{2}}\right) u^{2}}_{\text {Rotational mass }} \dot{v} .
$$

These losses are reduced to an equivalent rotational mass, which is multiplied by the rear-wheel acceleration $\dot{v}$ to obtain a force component. The validation of the traction force $F_{\mathrm{T}}$ is made within the wheel force validation in Section 3.4. In the case of acceleration, the longitudinal rear-wheel force is the traction force.

\subsection{Mass estimator}

As mentioned in the introduction, estimation of the vehicle mass is particularly important for motorcycles. The empty weight of two-wheeled vehicles is less compared to passenger cars and thus the influence of the vehicle loading on customer loads increases. Furthermore, the vehicle mass is essential for the wheel force calculation. Several algorithms have already been published. Rozyn and Zhang [14] measured the sprung mass response to estimate the inertial parameters of the vehicle, which requires detailed knowledge about the suspension stiffness and the damping characteristics. Lingman and Schmidtbauer [9] used longitudinal vehicle dynamics and a KF that estimates both the road slope and the vehicle mass. Fathy et al. [15] developed a recursive least-square model to estimate the vehicle mass. This study uses an approach based on resistance forces and longitudinal dynamics for mass estimation, as Ritzen et al. [16-18] proposed for heavy-duty vehicles. Figure 6 illustrates the longitudinal dynamics with external forces acting on the motorcycle. The dynamic equation of motion can be solved for the vehicle mass $m$, see Equations (15)-(17).

$$
\begin{gathered}
m \dot{v}=F_{\mathrm{T}}-F_{\mathrm{D}}-F_{\mathrm{S}}-F_{\mathrm{R}}, \\
F_{\mathrm{D}}=\frac{1}{2} \rho c_{x} A v^{2}=\kappa v^{2}, \quad F_{\mathrm{S}}=m g \sin \alpha, \quad F_{\mathrm{R}}=m g f_{\mathrm{r}} \cos \alpha, \\
m=\frac{F_{\mathrm{T}}-\kappa v^{2}}{\dot{v}+g\left(\sin \alpha+f_{\mathrm{r}} \cos \alpha\right)} .
\end{gathered}
$$

$F_{\mathrm{D}}$ is the aerodynamic drag force and $F_{\mathrm{T}}$ is the traction force acting on the rear wheel, as derived in Equation (14). The aerodynamic coefficients were obtained from 


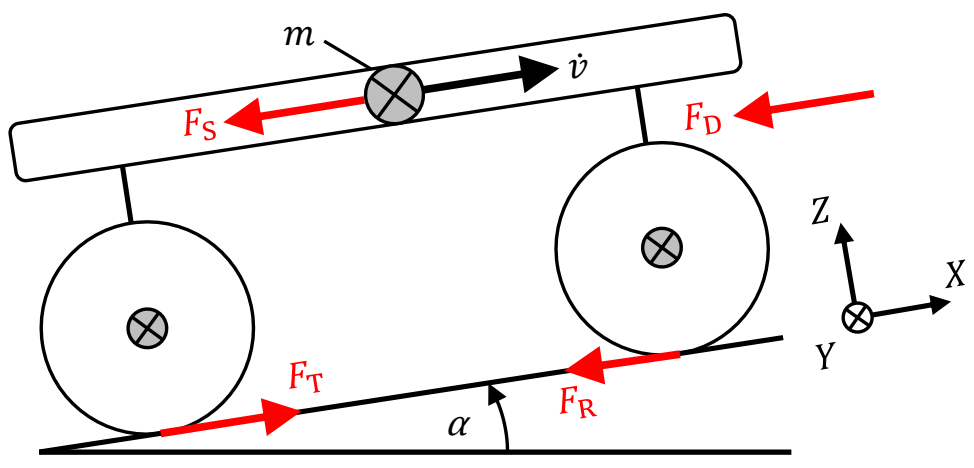

Figure 6 - External forces acting on the motorcycle.

measurements in a wind tunnel of BMW. They are substituted by the single constant $\kappa$. The slope resistance force $F_{\mathrm{S}}$ depends on the road slope angle $\alpha$, which is estimated with the road slope estimator. The rolling resistance force $F_{\mathrm{R}}$ is calculated with a constant rolling resistance coefficient $f_{\mathrm{r}}$.

Since the input signals are affected by measurement noise as well as model uncertainties from the road slope estimator and the driveline model, a direct calculation of the vehicle mass is infeasible. For this reason, the estimation problem was formulated with the help of an extended Kalman filter (EKF). The application of a linear KF is infeasible because the process equations are nonlinear. The EKF can handle nonlinear stochastic difference equations, such as Equations (18)-(19).

$$
\begin{aligned}
& \boldsymbol{x}_{k}=f\left(\boldsymbol{x}_{k-1}, \boldsymbol{u}_{k-1}, \boldsymbol{q}_{k-1}\right), \\
& \boldsymbol{z}_{k}=h\left(\boldsymbol{x}_{k}, \boldsymbol{r}_{k}\right) .
\end{aligned}
$$

Welch and Bishop [13] highlight that the EKF linearises around the current mean and covariance and that the most interesting and successful applications have been solved with EKFs. Jacobian matrices $\mathbf{A}, \mathbf{W}, \mathbf{H}$, and $\mathbf{N}$ are required for the linearisation. The basic operations for the EKF are the same as for the linear KF. To define the problem in state-space representation, Equation (17) can be solved for the vehicle acceleration $\dot{v}$, see Equation (20).

$$
\dot{v}=\frac{\left(F_{\mathrm{T}}-\kappa v^{2}\right)}{m}-g\left(\sin \alpha+f_{\mathrm{r}} \cos \alpha\right)
$$

The state vector $\boldsymbol{x}_{\mathrm{m}}$ is defined by the velocity $v$ and the reciprocal mass $\Theta$, as shown in 
Equation (21). The subscript ' $\mathrm{m}$ ' indicates that the state vector is formulated to estimate the vehicle mass.

$$
\boldsymbol{x}_{\mathrm{m}}=\left(\begin{array}{c}
v \\
\Theta
\end{array}\right), \quad \Theta=\frac{1}{m} .
$$

The substitution of $\Theta=1 / \mathrm{m}$ leads to a more robust formulation of the estimation problem. The measurement vector $\boldsymbol{z}_{\mathrm{m}} \in \mathrm{Re}^{m}$ is defined by the measured velocity $v$. Finally, the state-space representation is obtained, see Equations (22)-(24).

$$
\begin{gathered}
\dot{\boldsymbol{x}}_{\mathrm{m}}=\left(\begin{array}{c}
\Theta \Gamma-g \Lambda \\
0
\end{array}\right) \quad \text { with } \\
\Gamma=F_{\mathrm{T}}-\kappa v^{2}, \quad \Lambda=\sin \alpha+f_{\mathrm{r}} \cos \alpha \\
\boldsymbol{z}_{\mathrm{m}}=v .
\end{gathered}
$$

The explicit discrete time-invariant formulation of the problem can be derived with the use of explicit Euler forward integration, see Equations (25)-(29), where $s$ is the time step size.

$$
\begin{gathered}
\boldsymbol{x}_{\mathrm{m} \mid k}=f\left(\boldsymbol{x}_{\mathrm{m} \mid k-1}, \boldsymbol{u}_{\mathrm{m} \mid k-1}, \boldsymbol{q}_{\mathrm{m} \mid k-1}\right)=\left(\begin{array}{c}
v_{k-1}+s\left[\Theta_{k-1} \Gamma_{k-1}-g \Lambda_{k-1}\right] \\
\Theta_{k-1}+q_{\mathrm{m}_{4} \mid k-1}
\end{array}\right) \text { with } \\
\Gamma_{k-1}=F_{\mathrm{T} \mid k-1}\left(1+q_{\mathrm{m}_{1} \mid k-1}\right)-\kappa\left(v_{k-1}+q_{\mathrm{m}_{2} \mid k-1}\right)^{2} \\
\Lambda_{k-1}=\sin \left(\alpha_{k-1}+q_{\mathrm{m}_{3} \mid k-1}\right)+f_{\mathrm{r}} \cos \left(\alpha_{k-1}+q_{\mathrm{m}_{3} \mid k-1}\right) \\
\boldsymbol{u}_{\mathrm{m}}=\left(\begin{array}{c}
F_{\mathrm{T}} \\
\alpha
\end{array}\right) \\
\boldsymbol{z}_{\mathrm{m} \mid k}=h\left(\boldsymbol{x}_{\mathrm{m} \mid k}, \boldsymbol{r}_{\mathrm{m} \mid k}\right)=\underbrace{\left[\begin{array}{ll}
1 & 0
\end{array}\right]}_{\mathbf{H}_{\mathrm{m}}} \underbrace{\left(\begin{array}{c}
v_{k} \\
\Theta_{k}
\end{array}\right)}_{\boldsymbol{x}_{\mathrm{m} \mid k}}+r_{\mathrm{m} \mid k} .
\end{gathered}
$$

While the process equations are nonlinear, the measurement equation remains linear. The process noise $\boldsymbol{q}_{\mathrm{m}}$ is modelled as normally distributed white noise. The noise influence $q_{\mathrm{m}_{1}}$ is modelled as a percentage amount of the traction force $F_{\mathrm{T}}$, since the model uncertainties for the traction force increase with a higher engine torque. The unknown wind speed is considered with the noise $q_{\mathrm{m}_{2}}$. Additionally, the noises $q_{\mathrm{m}_{3}}$ and $q_{\mathrm{m}_{4}}$ are 
added to the road slope angle $\alpha$ and the reciprocal vehicle mass $\Theta$ to consider model uncertainties. The measurement noise $\boldsymbol{r}_{\mathrm{m}}$ is added to the measured velocity $v$. The control input vector $\boldsymbol{u}_{\mathrm{m}}$ comprises the traction force $F_{\mathrm{T}}$ and the road slope angle $\alpha$. The Jacobian matrices $\mathbf{A}_{\mathrm{m}}, \mathbf{W}_{\mathrm{m}}, \mathbf{H}_{\mathrm{m}}$, and $\mathbf{N}_{\mathrm{m}}$ need to be derived to apply the EKF, see Equations (30)-(34).

$$
\begin{aligned}
& \mathbf{A}_{\mathrm{m}[i, j]}=\frac{\partial f_{[i]}}{\partial x_{\mathrm{m}[j]}}\left(\boldsymbol{x}_{\mathrm{m} \mid k-1}, \boldsymbol{u}_{\mathrm{m} \mid k-1}, 0\right), \quad \mathbf{W}_{\mathrm{m}[i, j]}=\frac{\partial f_{[i]}}{\partial q_{\mathrm{m}[j]}}\left(\boldsymbol{x}_{\mathrm{m} \mid k-1}, \boldsymbol{u}_{\mathrm{m} \mid k-1}, 0\right), \\
& \mathbf{H}_{\mathrm{m}[i, j]}=\frac{\partial h_{[i]}}{\partial x_{\mathrm{m}[j]}}\left(\boldsymbol{x}_{\mathrm{m} \mid k}, 0\right), \quad \quad \mathbf{N}_{\mathrm{m}[i, j]}=\frac{\partial h_{[i]}}{\partial r_{\mathrm{m}[j]}}\left(\boldsymbol{x}_{\mathrm{m} \mid k}, 0\right), \\
& \mathbf{A}_{\mathrm{m}}=\left[\begin{array}{cc}
1-2 \kappa s v_{k-1} \Theta_{k-1} & s \Gamma_{k-1} \\
0 & 1
\end{array}\right], \\
& \mathbf{W}_{\mathrm{m}}=\left[\begin{array}{cccc}
s \Theta_{k-1} F_{\mathrm{T} \mid k-1} & -2 s \kappa \Theta_{k-1} v_{k-1} & -s g\left(\cos \alpha_{k-1}-f_{\mathrm{r}} \sin \alpha_{k-1}\right) & 0 \\
0 & 0 & 0 & 1
\end{array}\right] \text {, } \\
& \mathbf{H}_{\mathrm{m}}=\left[\begin{array}{ll}
1 & 0
\end{array}\right], \quad \mathbf{N}_{\mathrm{m}}=1 .
\end{aligned}
$$

The model assumes valid acceleration events that are suitable for the mass estimation. Hence, a second on/off logic was formulated for the mass estimator. The restrictions are designed to be strict to identify evaluable acceleration events, which makes the mass estimation more robust. For this reason, the algorithm pauses during cornering of the motorcycle. Additionally, the engine torque model is only valid for steady-state conditions of the engine. For the mass estimation, this means that the traction force $F_{\mathrm{T}}$ must not change more than a given threshold. To sum up, the conditions to identify valid acceleration events are as follows:

- Absolute value of the angular yaw rate is lower than a given threshold.

- Traction force is higher than a given threshold.

- Derivative of the traction force is lower than a given threshold.

The thresholds were evaluated empirically and as a consequence, they can differ for other motorcycles and underlying models. If a condition is violated, the algorithm holds the mass estimation until all conditions are true again. Despite these strict conditions, the results can still vary for different acceleration events since several other influences are not considered. Therefore, another linear filter was implemented to calculate the running mean of the estimated mass. When the conditions are violated or no converged 
mass estimate is available, the last valid mass estimate is forwarded to the wheel force calculation. The start value for the algorithm is defined as a standard mass with a normal rider weight. Please note that these restrictions are valid for the mass estimator only. Nevertheless, there is a continuous output of the mass estimate for the subsequent wheel force calculation.

\subsection{Wheel force calculation}

A model-based wheel force calculation was developed, whereby the individual mechanical effects are calculated for the particular rigid bodies. This modular approach makes a subsequent composition of the wheel forces possible. The method is based on the following assumptions: A motorcycle is modelled with three rigid bodies for sprung mass, rear unsprung mass, and front unsprung mass, as Cossalter described in [19]. These models exist in a variety of publications, see e.g. [6, 10, 19, 20]. They differ in complexity and degrees of freedom for their individual application. The sprung mass comprises the frame, the engine, and the rider. Additionally, parts of the front and rear suspension system are counted to the sprung mass. The sprung mass is lumped in the centre of gravity (COG). The rear unsprung mass comprises the rear wheel, the rear brake, and parts of the rear suspension. The front unsprung mass comprises the front wheel, the front brake, and parts of the front suspension. Figure 7 shows the motorcycle model together with the three rigid bodies and the global reference frame. Furthermore, the main geometric dimensions are illustrated: wheelbase $p$, height of the COG $h_{\operatorname{cog} \mid 0}$ and perpendicular distance $l_{\operatorname{cog}}$ of the COG from the rear wheel $Z$-axis. The degrees of freedom of the rigid bodies were formulated according to their equivalent onboard sensor. This means that every degree of freedom is represented by a signal from the onboard sensors. The sprung mass has the following four degrees of freedom:

- Displacement in $X$ and $Z$.

- Roll motion around tyre contact patch line.

- Yaw motion around vehicles $Z$-axis.

The unsprung masses have one degree of freedom in vertical direction, while the wheels can rotate around their axes. Steering and rotation of the handlebars are neglected, because they are not yet part of the onboard signals. This means that every roll motion acts on the three bodies with the same amount. The illustrated model considers no springs or dampers, because they are not required for the modular approach. The wheel forces are calculated from the measured responses of the particular rigid bodies, which means displacements, velocities, and accelerations. These kinds of problems are defined 


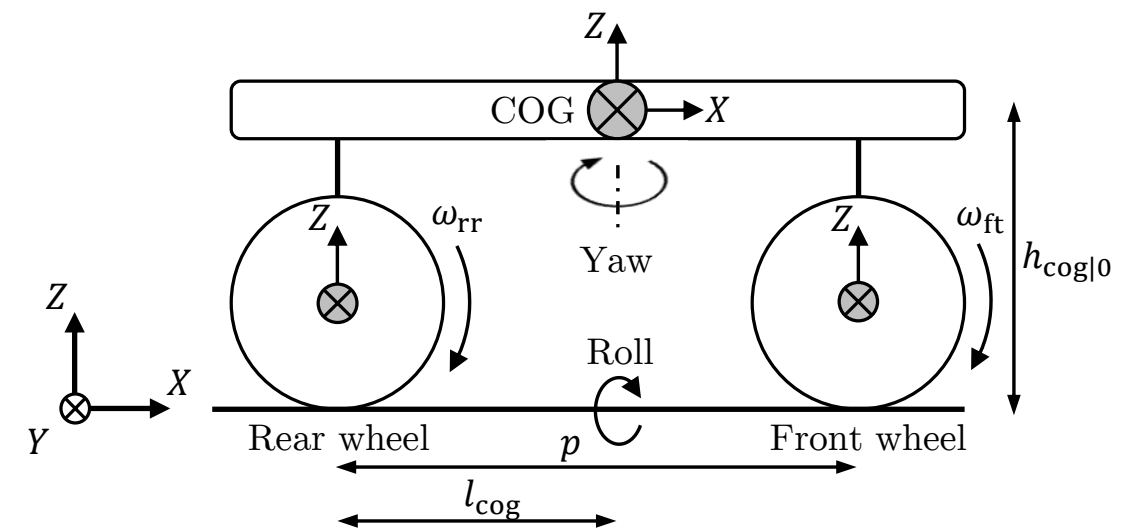

Figure 7 - Motorcycle model with three rigid bodies.

Table 1 - Required onboard signals for the wheel force calculation.

\begin{tabular}{lcccl}
\hline Description & Symbol & Unit & Filter type & Source \\
\hline Acceleration COG & $a_{x}, a_{z \mid r a w}$ & $\mathrm{~m} / \mathrm{s}^{2}$ & Low-pass & IMU \\
Angular rates COG & $\omega_{x}, \omega_{y}, \omega_{z}$ & $\mathrm{~s}^{-1}$ & Low-pass & IMU \\
Velocity & $v$ & $\mathrm{~m} / \mathrm{s}$ & - & ABS sensor \\
Angular wheel rates & $\omega_{\mathrm{ft}}, \omega_{\mathrm{rr}}$ & $\mathrm{s}^{-1}$ & - & ABS sensor \\
Brake pressure & $p_{\mathrm{ft}}, p_{\mathrm{rr}}$ & $\mathrm{N} / \mathrm{m}^{2}$ & - & ABS sensor \\
Spring deflection & $s_{\mathrm{ft}}, s_{\mathrm{rr}}$ & $\mathrm{m}$ & High-pass & Suspension sensor \\
Road slope & $\alpha$ & $\circ$ & - & Road slope estimator \\
Mass & $m$ & $\mathrm{~kg}$ & - & Mass estimator \\
Traction force & $F_{\mathrm{T}}$ & $\mathrm{N}$ & - & Engine \& driveline model \\
Roll angle & $\varphi$ & $\circ$ & - & Engine ECU \\
\hline
\end{tabular}

as inverse dynamic problems. Table 1 shows the required onboard signals for the wheel force calculation.

As introduced in Section 2, the crossover frequency $f_{\mathrm{c}}$ is used to filter the measured accelerations to distinguish between forces acting on the sprung mass and forces generated by the unsprung mass excitation. This means that accelerations measured from the sprung mass are low-pass filtered, whereas accelerations measured from the unsprung masses are high-pass filtered with the crossover frequency $f_{\mathrm{c}}$. This differentiation guarantees that no excitation from the unsprung masses affects the force calculation of the sprung mass and vice versa. As the geometric dimensions of the COG change during banking of the motorcycle, they are defined as functions of the roll angle $\varphi$, see Equations (35)-(36). The out-of-plane component $d_{\operatorname{cog}}$ describes the lateral distance from COG to the $X$ - $Z$-plane. The measured acceleration in $Z$ is corrected for the same reason, see Equation (37). 


$$
\begin{array}{ll}
\text { Height of COG: } & h_{\operatorname{cog}}=h_{\operatorname{cog} \mid 0} \cos \varphi, \\
\text { Depth of COG: } & d_{\operatorname{cog}}=h_{\operatorname{cog} \mid 0} \sin \varphi,
\end{array}
$$

$$
\text { Acceleration COG in } Z: \quad a_{z}=a_{z \mid \mathrm{raw}} \cos \varphi \text {. }
$$

Dynamic equations of motion have been used to calculate the driving resistance forces and the inertial forces from the measured onboard signals. For a modular formulation of the final wheel force calculation, a subset of equations is derived, see Equations (38)(42). The centrifugal force can be derived from the equilibrium of moments around the $X$-axis, see Equation (43).

$$
\begin{aligned}
\text { Normal force: } & F_{\mathrm{N}}=m a_{z} \cos \alpha, \\
\text { Slope force: } & F_{\mathrm{S}}=m a_{z} \sin \alpha, \\
\text { Aerodynamic drag force: } & F_{\mathrm{D}}=\frac{1}{2} \rho c_{x} A v^{2}=\kappa v^{2}, \\
\text { Inertial force in } X: & F_{\mathrm{I} \mid X}=m a_{x}, \\
\text { Inertial moment around } X: & M_{\mathrm{Roll}}=I_{x} \dot{\omega}_{x}, \\
\text { Centrifugal force: } & F_{\mathrm{C}}=F_{\mathrm{N}} \tan \varphi-\frac{M_{\text {Roll }}}{h_{\operatorname{cog}}} .
\end{aligned}
$$

The forces from unsprung mass excitation can be derived with the measured spring deflections, see Equations (44)-(45).

$$
\begin{array}{ll}
\text { Front unsprung mass force: } & F_{\mathrm{un} \mid \mathrm{ft}}=m_{\mathrm{un} \mid \mathrm{ft}} \ddot{s}_{\mathrm{ft}}, \\
\text { Rear unsprung mass force: } & F_{\mathrm{un} \mid \mathrm{rr}}=m_{\mathrm{un} \mid \mathrm{rr}} \ddot{s}_{\mathrm{rr}}
\end{array}
$$

The spring deflections are first high-pass filtered with the crossover frequency $f_{\mathrm{c}}$ and subsequently differentiated twice to obtain the unsprung mass acceleration $\ddot{s}$. The rolling resistance forces depend on the vertical wheel forces and the rolling resistance coefficient $f_{\mathrm{r}}$, see Equations (46)-(47). 


$$
\begin{aligned}
\text { Rolling resistance force front: } & F_{\mathrm{R} \mid \mathrm{ft}}=F_{Z \mid \mathrm{ft}} f_{\mathrm{r}}, \\
\text { Rolling resistance force rear: } & F_{\mathrm{R} \mid \mathrm{rr}}=F_{Z \mid \mathrm{rr}} f_{\mathrm{r}} .
\end{aligned}
$$

The brake moments are calculated by multiplying the brake pressures $p$ by a linear brake coefficient $c$, which depends on the brake characteristics, e.g. quantity of brake pistons and friction values, see Equations (48)-(49).

$$
\begin{aligned}
\text { Brake moment of front wheel: } & M_{\mathrm{B} \mid \mathrm{ft}}=c_{\mathrm{ft}} p_{\mathrm{ft}}, \\
\text { Brake moment of rear wheel: } & M_{\mathrm{B} \mid \mathrm{rr}}=c_{\mathrm{rr}} p_{\mathrm{rr}} .
\end{aligned}
$$

Equilibrium of forces and moments is applied on the motorcycle model to obtain the components of external wheel forces in $Y$ and $Z$. The wheel forces in vertical direction are calculated as follows:

$$
\begin{aligned}
& F_{Z \mid \mathrm{ft}}=\frac{F_{\mathrm{N}} l_{\operatorname{cog}}}{p}-\frac{F_{\mathrm{S}} h_{\mathrm{cog}}}{p}-\frac{F_{\mathrm{D}} h_{\mathrm{cog}}}{p}-\frac{F_{\mathrm{I} \mid X} h_{\mathrm{cog}}}{p}+F_{\mathrm{un} \mid \mathrm{ft}} \cos \varphi, \\
& F_{Z \mid \mathrm{rr}}=\underbrace{\frac{F_{\mathrm{N}}\left(p-l_{\operatorname{cog}}\right)}{p}}_{\begin{array}{c}
\text { Steady } \\
\text { state }
\end{array}}+\underbrace{\frac{F_{\mathrm{S}} h_{\mathrm{cog}}}{p}}_{\begin{array}{c}
\text { Slope } \\
\text { resistance }
\end{array}}+\underbrace{\frac{F_{\mathrm{D}} h_{\mathrm{cog}}}{p}}_{\begin{array}{c}
\text { Aerodynamic } \\
\text { resistance }
\end{array}}+\underbrace{\frac{F_{\mathrm{I} \mid X} h_{\mathrm{cog}}}{p}}_{\begin{array}{c}
\text { Inertial } \\
\text { force X }
\end{array}}+\underbrace{F_{\mathrm{un} \mid \mathrm{rr}} \cos \varphi}_{\begin{array}{c}
\text { Unsprung } \\
\text { masses }
\end{array}} .
\end{aligned}
$$

The equations are not summarised to describe the particular components of the wheel force calculation. The load distribution of the normal force $F_{\mathrm{N}}$ affects both the front and rear-wheel vertical force depending on the longitudinal location $l_{\operatorname{cog}}$ of the COG and the wheelbase $p$. The other resistance forces are added to the vertical wheel forces depending on the height $h_{\mathrm{cog}}$ of the COG. The resistance and inertia forces in negative $X$ direction lead to a decrease in the vertical front-wheel force and vice versa. The forces from unsprung mass excitation are added depending on the roll angle $\varphi$. The centrifugal force $F_{\mathrm{C}}$ affects the lateral force components depending on the load distribution. Due to banking of the motorcycle, the resistance forces act on the lateral force components depending on the out of plane component $d_{\mathrm{cog}}$. The forces from unsprung mass excitation are added, respectively. Equations (52)-(53) show the calculation of the lateral wheelforce components. 


$$
\begin{aligned}
& F_{Y \mid \mathrm{ft}}=\frac{F_{\mathrm{C}} l_{\mathrm{cog}}}{p}-\frac{F_{\mathrm{S}} d_{\mathrm{cog}}}{p}-\frac{F_{\mathrm{D}} d_{\mathrm{cog}}}{p}-\frac{F_{\mathrm{I} \mid X} d_{\mathrm{cog}}}{p}+F_{\mathrm{un} \mid \mathrm{ft}} \sin \varphi, \\
& F_{Y \mid \mathrm{rr}}=\underbrace{\frac{F_{\mathrm{C}}\left(p-l_{\mathrm{cog}}\right)}{p}}_{\begin{array}{c}
\text { Centrifugal } \\
\text { force }
\end{array}}+\underbrace{\frac{F_{\mathrm{S}} d_{\mathrm{cog}}}{p}}_{\begin{array}{c}
\text { Slope } \\
\text { resistance }
\end{array}}+\underbrace{\frac{F_{\mathrm{D}} d_{\mathrm{cog}}}{p}}_{\begin{array}{c}
\text { Aerodynamic } \\
\text { resistance }
\end{array}}+\underbrace{\frac{F_{\mathrm{I} \mid X} d_{\mathrm{cog}}}{p}}_{\begin{array}{c}
\text { Inertial } \\
\text { force X }
\end{array}}+\underbrace{F_{\mathrm{un} \mid \mathrm{rr}} \sin \varphi}_{\begin{array}{c}
\text { Unsprung } \\
\text { masses }
\end{array}} .
\end{aligned}
$$

The longitudinal wheel forces are calculated by the rotational equations of motion, see Equations (54)-(55). The traction force $F_{\mathrm{T}}$ acting on the rear wheel is already derived in Section 3.2 and the brake moments and the rolling resistance forces are added to complete the rotational equations of motion.

$$
\begin{aligned}
& F_{X \mid \mathrm{rr}}=F_{\mathrm{T}}-\frac{M_{\mathrm{B} \mid \mathrm{rr}}}{r_{\mathrm{rr}}}-F_{\mathrm{R} \mid \mathrm{rr}}, \\
& F_{X \mid \mathrm{ft}}=-\underbrace{\frac{I_{\mathrm{ft}} \dot{\omega}_{\mathrm{ft}}}{r_{\mathrm{ft}}}}_{\begin{array}{c}
\text { Wheel } \\
\text { dynamics }
\end{array}}-\underbrace{\frac{M_{\mathrm{B} \mid \mathrm{ft}}}{r_{\mathrm{ft}}}}_{\begin{array}{c}
\text { Brake } \\
\text { force }
\end{array}}-\underbrace{F_{\mathrm{R} \mid \mathrm{ft}}}_{\begin{array}{c}
\text { Rolling } \\
\text { resistance }
\end{array}} .
\end{aligned}
$$

\subsection{Rainflow counting method}

Rainflow counting of both external and internal loads is a standard practice in durability analysis, as described in $[1,21]$. As it is based on the Masing memory rule, it is a counting method with a direct relation to the physical background of the material and fatigue damage assessment. The algorithm extracts hysteresis loops from the measured or simulated load signals and stores them in a rainflow matrix. There are different standards for the rainflow counting method, e.g. ASTM Standard [22] and French ANFOR Standard [23]. In this paper, the four-point algorithm was implemented according to Clormann and Seeger [24] to count the calculated wheel forces. Once the rainflow matrices are collected, several other representations of hysteresis loops can be derived, e.g. range-mean matrix or level crossing counting. 


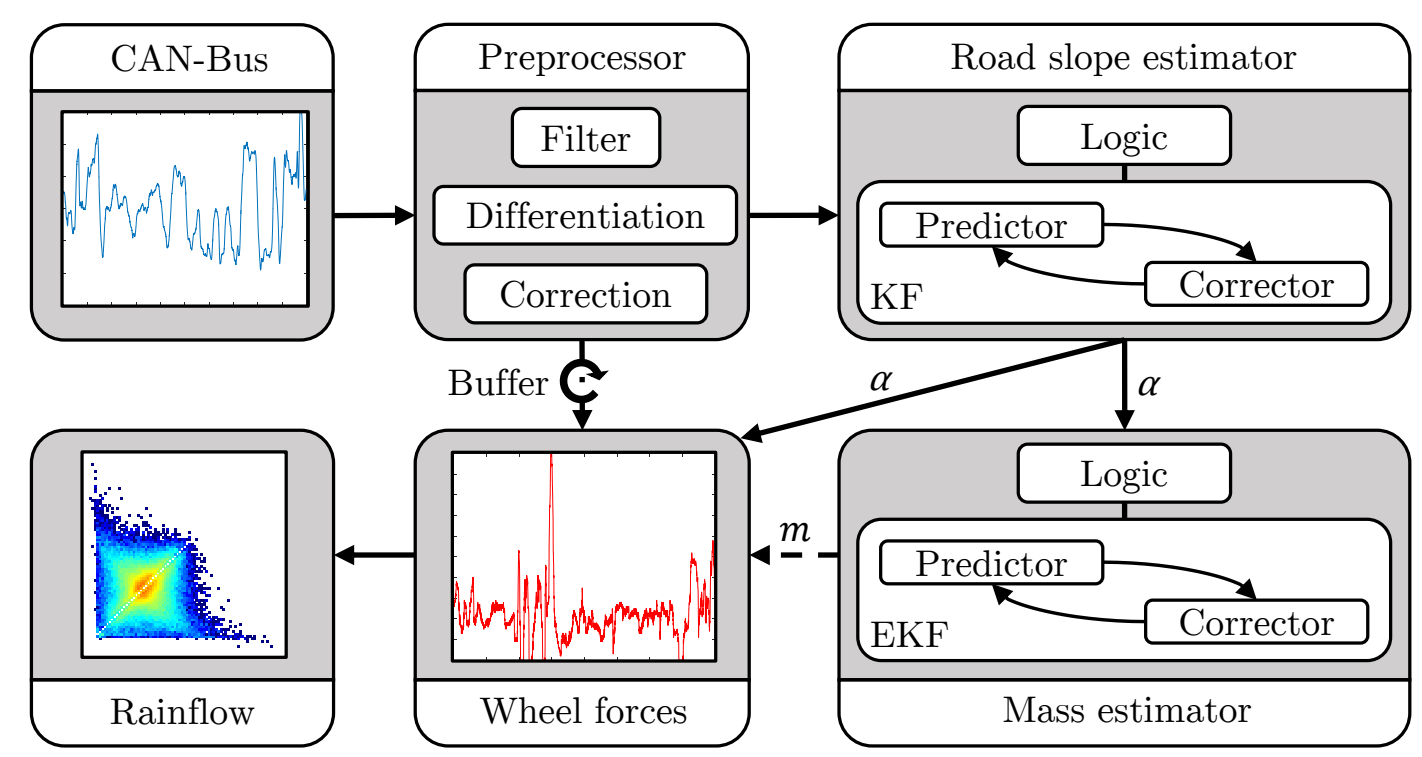

Figure 8 - Flow chart of the customer load estimation model.

\subsection{Whole model}

Figure 8 shows the flow chart of the whole model to estimate the customer loads. In summary, a preprocessor filters the measured onboard signals and calculates derivatives for the following algorithms. A correction module ensures that no drifts and offsets occur. It also takes into account the fact that geometric and inertial parameters change during time, e.g. the location of COG during banking of the motorcycle. Additionally, the traction force is calculated based on the driveline model. Once the signals are prepared, the road slope estimator computes the current road slope angle $\alpha$ with a linear KF. The road slope is essential for the mass estimation and the wheel force calculation. The road slope estimator has its own limitations, although it still provides a slope angle for the following algorithms at any time, as described in Section 3.1. The mass estimator calculates an estimate for the vehicle mass $m$ based on valid acceleration events with the help of an EKF. Once the vehicle mass value has converged, it is forwarded to the wheel force calculation. In case the converged estimate of the vehicle mass is unavailable, an initial mass for a full-fuelled motorcycle with a normal rider weight is provided, as described in Section 3.3. Since the road slope estimator causes a delay, a signal buffer was implemented to synchronise all of the input values for the wheel force calculation. As the algorithm itself has no limitations, the wheel force calculation continuously computes forces. The equations are valid under all driving conditions. Linear finite impulse 
response filters (FIR) were implemented. They are designed to have a linear phase delay, which makes the synchronisation of all required signals feasible. Hamming [25] provides further information about digital filters. Finally, the four-point algorithm counts the calculated wheel forces with the rainflow method.

\section{Validation}

\subsection{Validation of the road slope estimator}

Test runs were performed with the reference motorcycle at the proving ground of BMW to validate the road slope estimator. The proving ground has a track including artificial hills with pre-defined road slopes, where the algorithm was validated at different velocities. Figure 9 shows the results from two runs together with the associated road slopes of the proving ground, which are $\alpha=12 \%,-16 \%, 32 \%$ and $-20 \%$. The road slope estimator works as expected at the proving ground. The vehicle speed shows only a slight influence on the algorithm. A mountain track ride was performed for a validation of the algorithm under real conditions with braking and cornering manoeuvres. GPS devices were mounted on the motorcycle to measure the absolute altitude for the validation. The mountain track was driven upwards and downwards to validate both positive and negative slope angles. The estimated road slope was integrated over the travelled distance to compare the calculated elevation profile with the GPS altitude, as shown in Figure 10. The integration was made with the start value from the measured altitude to provide the same height at the start. The results show a close coincidence between the estimated and measured elevation profile. Since the mountain track is within a forest and thus the GPS signal can be corrupted, the spikes in the GPS altitude signal are potentially caused by noise and GPS errors. 


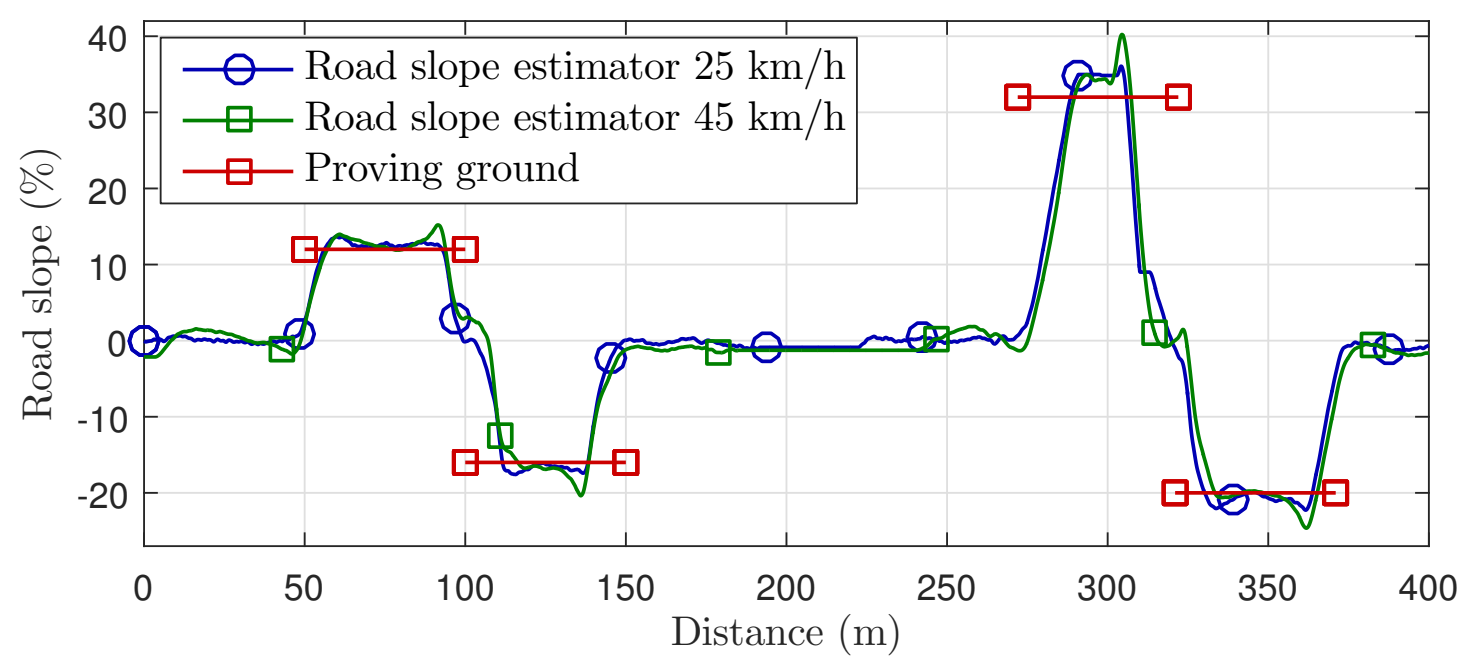

Figure 9 - Validation of the road slope estimator at the proving ground.

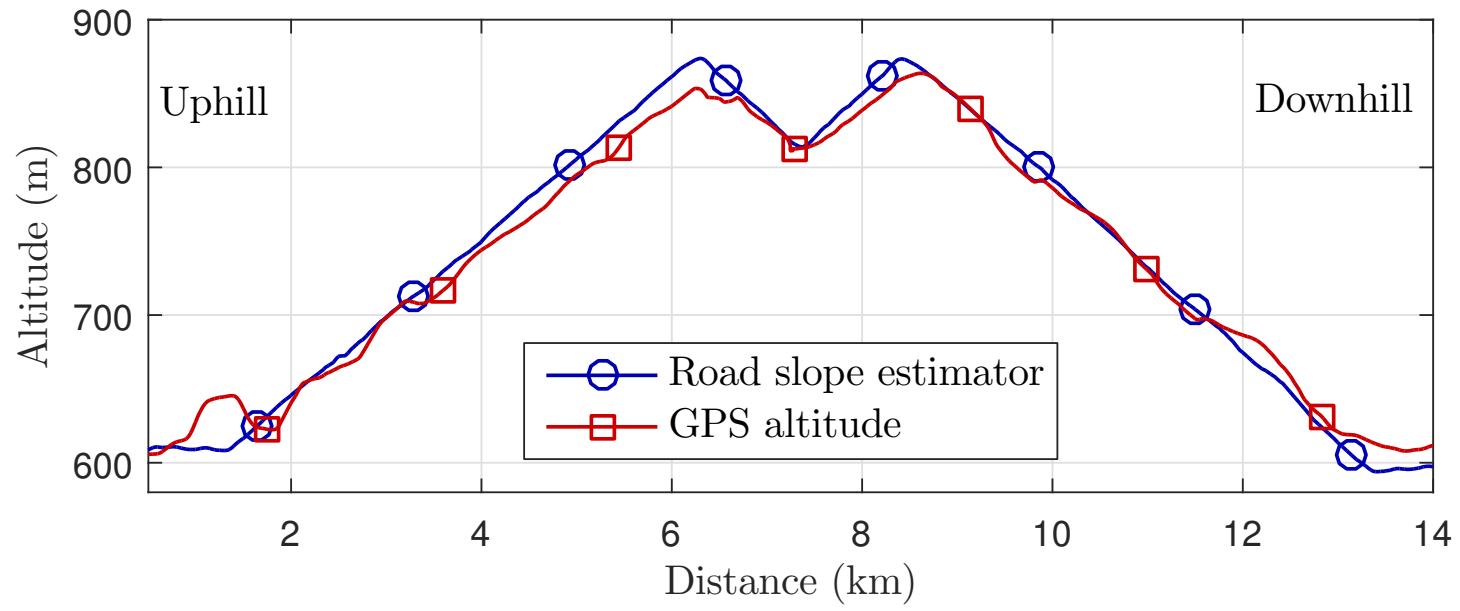

Figure 10 - Validation of the road slope estimator at the mountain track. 


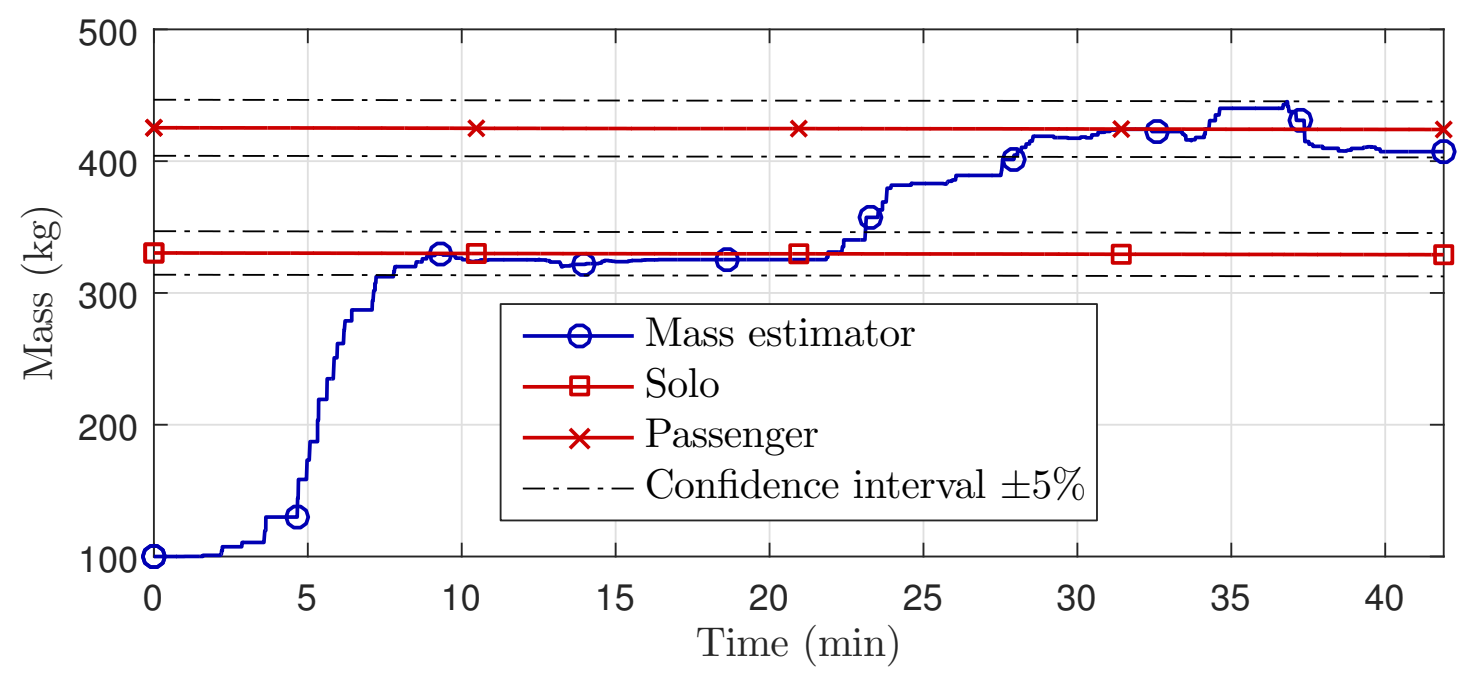

Figure 11 - Validation of the mass estimator.

\subsection{Validation of the mass estimator}

A test ride with a change in the vehicle mass was carried out to validate the mass estimator, based upon the following setup: the rider drives the motorcycle about $20 \mathrm{~min}$, before a passenger was added to the vehicle to analyse the convergence behaviour of the algorithm. The results from this test ride are shown in Figure 11. The vehicle mass, the driver mass, and the passenger mass were measured in advance. These true reference weights are illustrated with solid lines $\left(m_{\text {solo }}=330 \mathrm{~kg}\right.$ and $\left.m_{\text {passenger }}=424 \mathrm{~kg}\right)$. For validation of the convergence behaviour of the algorithm, the start value was intentionally set up to an incorrect value of $m_{0}=100 \mathrm{~kg}$. The mass estimation converged after eight min. The quality criterion for the mass estimator is to converge within the confidence interval, which is defined to be $\pm 5 \%$ of the true value. After $22 \mathrm{~min}$, the passenger got onto the motorcycle, which can be seen by the rise of the vehicle mass estimation. The mass estimation converged within a few minutes and strongly depends on the quantity of valid acceleration events. Several test rides were performed for empirical KF tuning.

\subsection{Validation of the wheel force calculation}

For validation of the calculated wheel forces, several test rides with wheel-load transducers have been accomplished. Different manoeuvres were analysed to evaluate the particular physical phenomena of the wheel force calculation. As described in Section 3.4, four different phenomena affect the longitudinal wheel forces: traction force, brake force, rolling resistance force, and inertial forces. All of these effects appear together in the test 


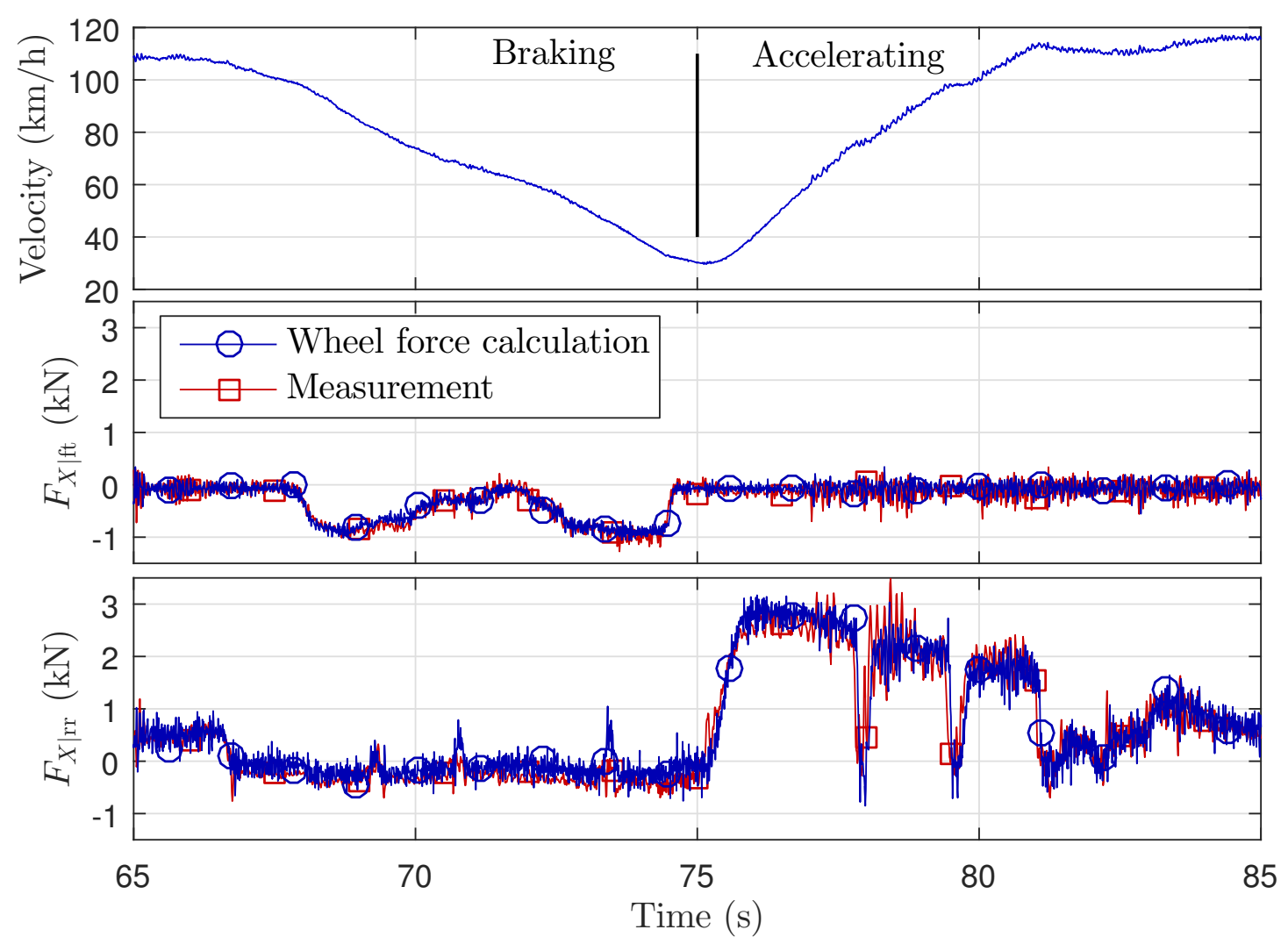

Figure 12 - Validation of the longitudinal wheel forces.

manoeuvre, as can be seen in Figure 12.

The comparison shows a manoeuvre with longitudinal wheel forces for both the front and rear wheel during braking and accelerating. For the braking part, the rolling resistance force induces a small offset, while the brake force accounts for the main part of the longitudinal front-wheel force $F_{X \mid \mathrm{ft}}$. This is overlaid by the rotational wheel dynamics, which induces a high-frequency oscillation. For the acceleration part, the traction force $F_{\mathrm{T}}$ of the rear wheel is the main contributor to the longitudinal rear-wheel force $F_{X \mid \mathrm{rr}}$. When accelerating, gear shifting disrupts the traction force, because opening of the clutch decouples the engine from the rear wheel. Again, a high-frequency oscillation from the rotational wheel dynamics is overlaid. To compare the calculated wheel forces in vertical and lateral direction with the measurement, they need to be combined to a resultant force $F_{Y Z}$ in the $Y$ - $Z$-plane. A coordinate transformation with the roll angle $\phi$ is unsuitable in this case. This is because the measured wheel forces actually act at the wheel hub, whereas the calculated wheel forces act between the road surface and the tyre. For a validation of the algorithm, the forces are thus summarised to resultant forces, as 


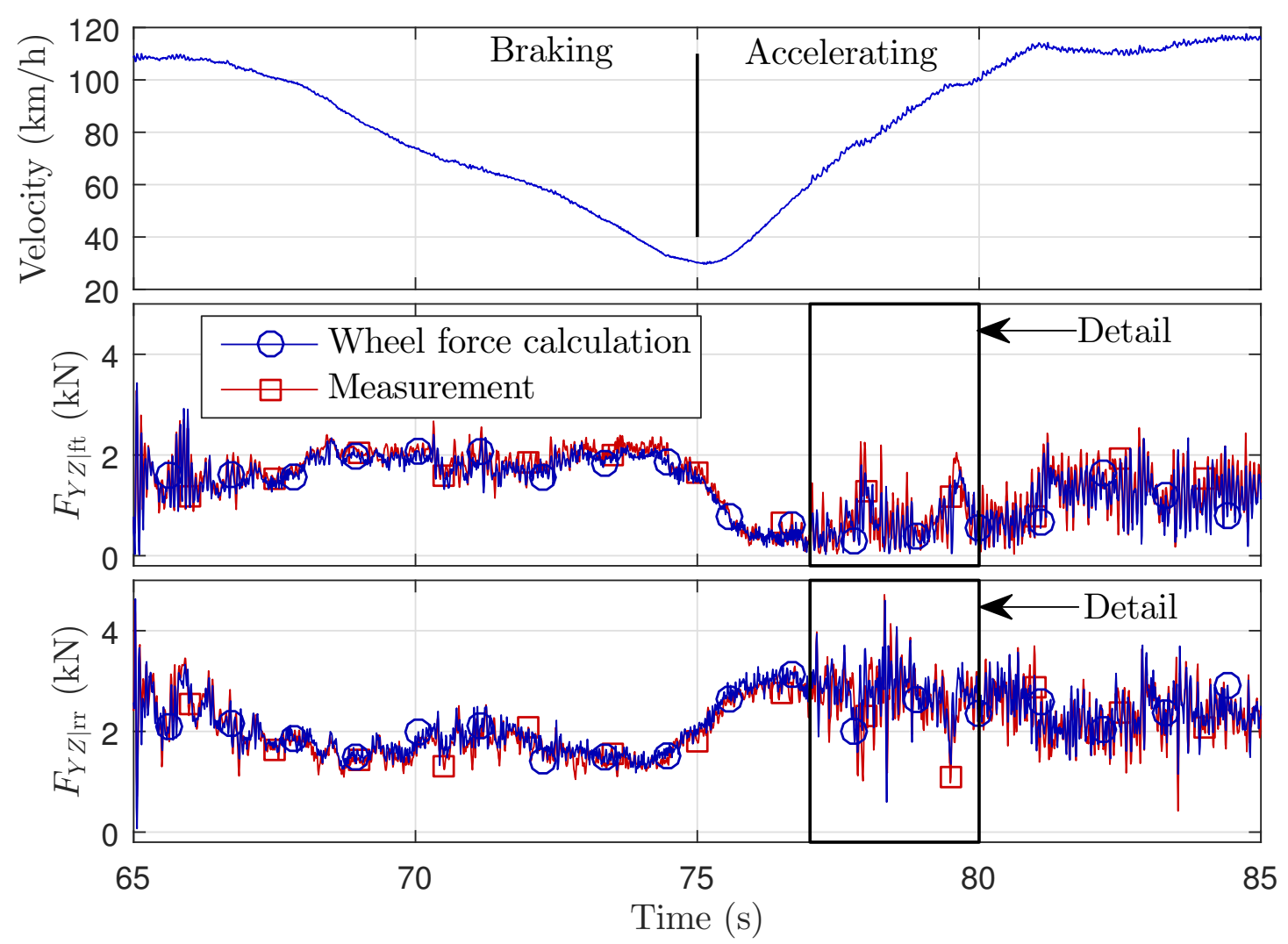

Figure 13 - Validation of the resultant wheel forces in the $Y$ - $Z$-plane.

shown in Figure 13 for the same manoeuvre. The load transfer induces a rise of the resultant front-wheel force $F_{Y Z \mid \mathrm{ft}}$ during braking. The acceleration manoeuvre causes the contrary and leads to a rise of the resultant rear-wheel force $F_{Y Z \mid \mathrm{rr}}$. Besides the effect of load transfer, the dynamics of the unsprung masses can be seen as a high-frequency oscillation. Figure 14 shows an extract from $t=77 \mathrm{~s}-80 \mathrm{~s}$ in further detail. The frequency of the calculated wheel force oscillation generally coincides with the measured wheel force oscillation. However, small deviations of the amplitudes exist. This is due to the model assumptions and unaccounted effects. The comparison shows that the wheel force calculation can reproduce the main physical phenomena. It is common practice to compare the severity of the signals with counting methods, e.g. the rainflow counting method. In order to achieve a diverse load profile, several test runs were linked together.

The rainflow counting algorithm first discretises the signal levels of the load in $n$ equidistant bins and subsequently counts the hysteresis loops and stores them in the rainflow matrix. Figure 15 shows the comparison of the rainflow matrices from the measured and the calculated resultant rear-wheel forces in the $Y$ - $Z$-plane. The number 


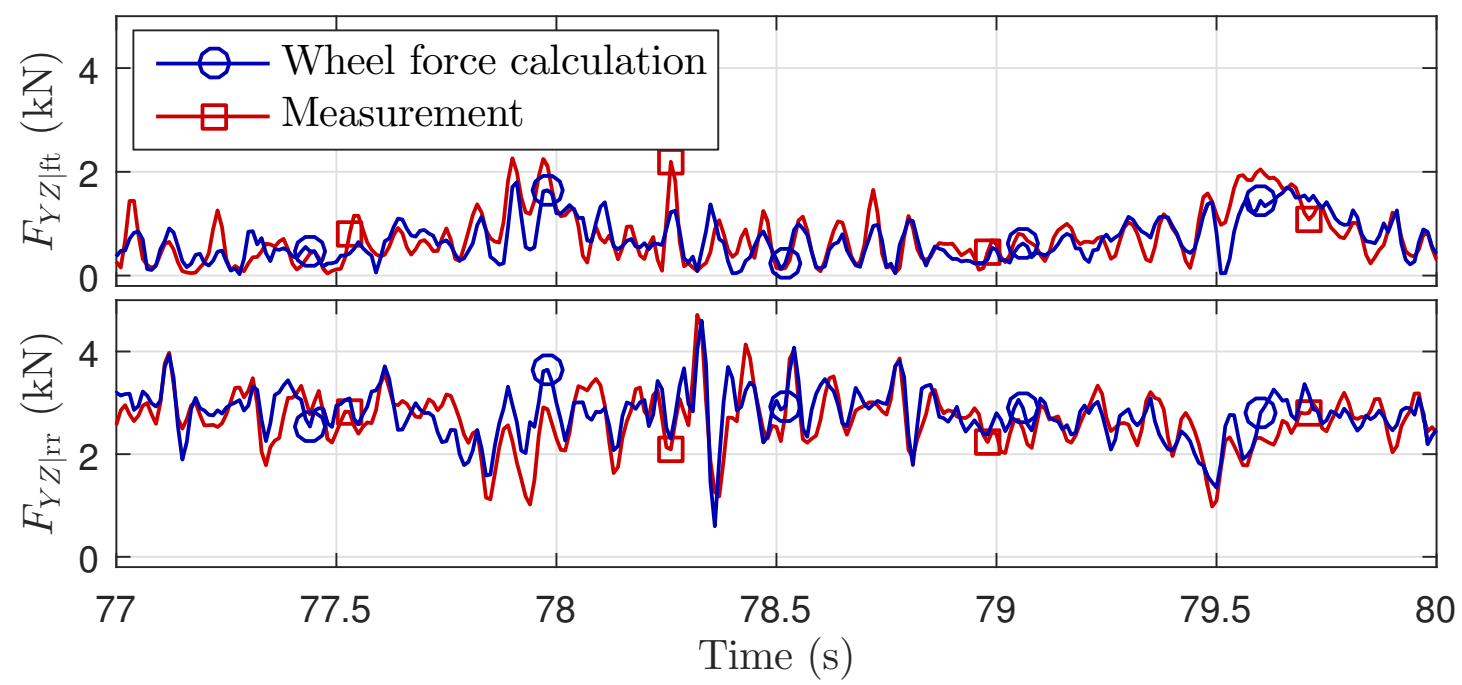

Figure 14 - Detailed extract of the resultant wheel forces.
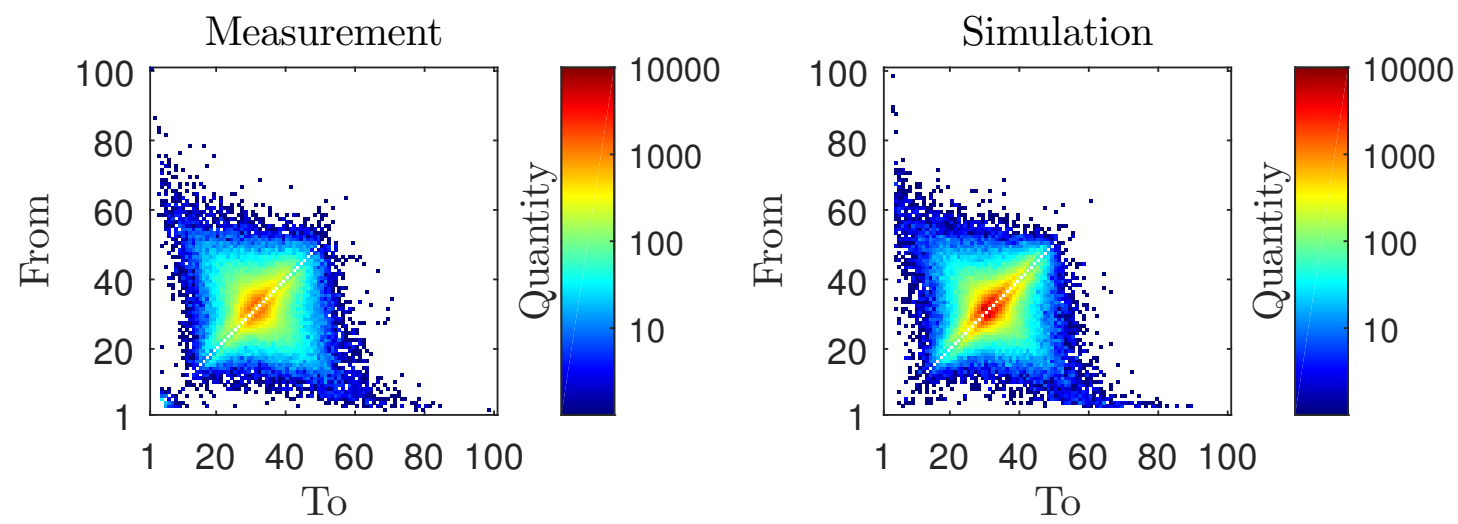

Figure 15 - Rainflow matrices of the resultant rear-wheel forces in the $Y$ - $Z$-plane.

of bins is chosen to $n=100$. The axes represent the container number in which the amplitude cycle starts (From) and ends (To). The colour represents the quantity of counted cycles on a logarithmic scale. The rainflow matrices look similar in their form and shape. This indicates that the magnitudes of the load oscillations are correct. The comparison of the midpoints of the rainflow matrices also indicates that the mean values coincides. A common practice in durability analysis is to reduce the effect of severity to one comparable value, the so-called pseudo-damage number $d$ [1]. The algorithm is based on the Palmgren-Miner rule, which simply sums up the damage contributions of all cycles, see Equation (56). 
Table 2 - Pseudo damage ratio.

\begin{tabular}{lr}
\hline Wheel force component & $d_{\text {mes }} / d_{\text {sim }}$ \\
\hline$F_{Y Z \mid \mathrm{ft}}$ & 0.9995 \\
$F_{Y Z \mid \mathrm{rr}}$ & 0.9708 \\
$F_{X \mid \mathrm{ft}}$ & 1.0006 \\
$F_{X \mid \mathrm{rr}}$ & 1.0187 \\
\hline \multicolumn{2}{c}{$d=\sum_{i} S_{i}^{\beta}$}
\end{tabular}

The counted amplitudes $S$ are exponentiated by $\beta$, which is the damage exponent. The ratios of the pseudo-damage numbers for the different wheel force components are given in Table 2. The ratios of the pseudo-damage numbers show that all of the simulated wheel forces are within a confidence interval of $\pm 5 \%$ of the measured wheel forces.

\section{Summary and Conclusion}

The objective of this research was to develop a system that reveals the unknown customer loads of two-wheeled vehicles. The results show that a customer load estimation for two-wheeled vehicles with onboard signals is possible. By combining the methods from several studies, an independent and automated customer load acquisition system was developed. This system comprises three main subsystems: the road slope estimator, the mass estimator, and the wheel force calculation. To estimate the unknown road slope, a linear KF was developed with an on/off logic. The algorithm was tested successfully at a proving ground as well as on a mountain track. With the knowledge of the road slope, one major resistance force was revealed.

An automated mass detection is essential for the wheel force calculation. For this reason, an EKF was developed to estimate the vehicle mass. The algorithm is based on longitudinal vehicle dynamics and takes acceleration events into account, which were evaluated with an on/off logic. The algorithm was tested during several test rides and under different loading configurations. The results show that the vehicle mass estimation is possible within a confidence interval and that sudden changes in the vehicle mass are considered after a few minutes. At the small scale, the knowledge of the vehicle mass is important for the wheel force calculation and at the large scale the distribution gives useful information for vehicle design and reliability targets.

The wheel force calculation was developed based on a superposition of forces derived 
from the particular physical effects. The degrees of freedom of the three rigid bodies were chosen so that every relevant onboard signal could be used. All input signals for the wheel force calculation are synchronised with a signal buffer. The wheel force calculation computes continuous results and is valid under all operating conditions. The results show that the model covers the previously measured wheel forces in both quality and quantity. The integrated rainflow counting algorithm reduces the time history of the loads to hysteresis cycles, which makes a comparison between the customer service loads on the large scale possible. The developed wheel force calculation can be used to replace classical wheel force measurements with wheel-load transducers. Extra measurement equipment is no longer necessary and thus mounting time and material is saved. The presented methods work with respect to the model restrictions and are valid under normal operating conditions. Hence, this system is able to reveal operating loads. Infrequent severe events often cause the most damage to the parts and thus further research is planned to investigate the identification of special events with onboard signals.

Detailed knowledge of the customer load distribution provides information for product design targets and can be analysed for different product segments and different regional markets. Customer loads can be used for an incremental evolution of the design targets of existing products. Another benefit is the comparison between product segments and a transformation to new vehicle projects. Additionally, test rig loads can be derived from the customer load distribution. In general, customer loads offer a variety of possibilities throughout the automotive business.

Since no time and location stamps are collected, an implementation of the system is assumed to be uncritical in terms of data protection. The data are collected anonymously without personal relation. The customer distribution is treated statistically to derive values such as quantiles, which do not correspond to specific customers.

\section{References}

[1] P. Johannesson and M. Speckert, eds. Guide to load analysis for durability in vehicle engineering. Chichester: Wiley, 2013, p. 434.

[2] L. Müller. 'Mehrkörpermodell-basiertes Online Monitoring der Betriebsbeanspruchung am Beispiel eines Nutzfahrzeug-Demonstrators'. PhD thesis. Kaiserslautern: TU Kaiserslautern, 2011.

[3] C. Matz. 'Online Berechnung von Fahrwerkskräften auf Basis von Onboard-Sensorik'. PhD thesis. Clausthal: TU Clausthal, 2015.

[4] M. Karlsson. 'Load modelling for fatigue assessment of vehicles - a statistical approach'. PhD thesis. Göteborg, Sweden: Chalmers, Göteborg University, 2007. 
[5] M. Kuchler and R. Schrupp. 'Mehrkomponenten-Motorradmessnabe'. In: Measuring and testing techniques in the vehicle industry. Nuremberg, Germany: VDI, 20015 10-11 2001, pp. 249-278.

[6] M. Tanelli, M. Corno and S. M. Savaresi, eds. Modelling, simulation and control of two-wheeled vehicles. Chichester: Wiley, 2014, pp. 1-348.

[7] I. Boniolo, S. Corbetta and S. M. Savaresi. 'Attitude estimation of a motorcycle in a Kalman filtering framework'. In: 6th IFAC symposium advances in automotive control. Munich, Germany: IFAC, 20107 12-14 2010, pp. 779-784.

[8] A. Vahidi, A. Stefanopoulou and H. Peng. 'Recursive least squares with forgetting for online estimation of vehicle mass and road grade: theory and experiments'. In: Vehicle System Dynamics 43.1 (2005), pp. 31-55.

[9] P. Lingman and B. Schmidtbauer. 'Road slope and vehicle mass estimation using Kalman filtering'. In: Vehicle System Dynamics 37.1 (2002), pp. 12-23.

[10] M. Corno, P. Spagnol and S. M. Savaresi. 'Road slope estimation in bicycles without torque measurements'. In: IFAC Proceedings Volumes. Cape Town, South Africa: IFAC, 20148 24-29 2014, pp. 6295-6300.

[11] R. E. Kalman. 'A new approach to linear filtering and prediction problems'. In: $J$ Basic Eng 82.D (1960), pp. 35-45.

[12] P. S. Maybeck. Stochastics models, estimation, and control. 1st ed. New York: Academic Press, 1979, p. 444.

[13] G. Welch and G. Bishop. An introduction to the Kalman filter. Technical report TR 95-041. Chapel Hill (NC): Department of Computer Science, University of North Carolina at Chapel Hill, 2006.

[14] M. Rozyn and N. Zhang. 'A method for estimation of vehicle inertial parameters'. In: Vehicle System Dynamics 48.5 (2010), pp. 547-565.

[15] H. K. Fathy, D. Kang and J. L. Stein. 'Online vehicle mass estimation using recursive least squares and supervisory data extraction'. In: 2008 American Control Conference. Seattle (WA): IEEE, 20086 11-13 2008, pp. 1842-1848.

[16] E. Ritzen. 'Adaptive vehicle weight estimation'. MA thesis. Linköping, Sweden: Department of Electrical Engineering, Linköping University, 1998.

[17] E. J. Holm. 'Vehicle mass and road grade estimation using Kalman filter'. MA thesis. Linköping, Sweden: Department of Electrical Engineering, Linköping University, 2011.

[18] B. Lundin and A. Olsson. 'Estimation of vehicle mass using an extended Kalman filter'. MA thesis. Gothenburg, Sweden: Department of Signals and Systems, Chalmers University of Technology, 2012.

[19] V. Cossalter. Motorcycle Dynamics. 2nd ed. [place unknown]: LULU, 2006, p. 372.

[20] G. Savino, F. Giovannini, N. Baldanzini et al. 'Real-time estimation of road-tyre adherence for motorcycles'. In: Vehicle System Dynamics 51.12 (2013), pp. 18391852. 
[21] M. Köhler, S. Jenne, K. Pötter et al. Zählverfahren und Lastannahme in der Betriebsfestigkeit. Heidelberg: Springer Berlin Heidelberg, 2012.

[22] ASTM International. Standard practices for cycle counting in fatigue analysis. Standard No. E1049-85. West Conshohocken (PA): ASTM International, 2011.

[23] AFNOR. Fatigue sous sollicitations d'amplitude variable. Standard No. A03-406. La Plaine Saint-Denis, France: AFNOR, 1993.

[24] U. H. Clormann and T. Seeger. 'RAINFLOW - HCM. Ein Zählverfahren für Betriebsfestigkeitsnachweise auf werkstoffmechanischer Grundlage'. In: Stahlbau 55.3 (1986), pp. 65-71.

[25] R. W. Hamming. Digital filters. 3rd ed. Mineola (NY): Dover Publications, Inc., 1998, p. 304. 